\title{
Determination of Carbonate Concentrations in Calcareous Soils with Common Vinegar Test ${ }^{1}$
}

\author{
Qiang Zhu, Yuncong Li, Guodong Liu, and Monica Ozores-Hampton²
}

\section{Introduction}

Calcareous soils are those that have free calcium carbonate $\left(\mathrm{CaCO}_{3}\right)$ and $\mathrm{pH}$ values in the range of 7.0 to 8.3. If they are managed properly, calcareous soils can be used to grow most crops, excluding those requiring acidic growth media, such as blueberry. Before employing any management practices, it is important to know how much carbonate exists in the soil. Soil carbonate is usually quantified in the laboratory by acid dissolution followed by the volumetric analysis of the released carbon dioxide $\left(\mathrm{CO}_{2}\right)$. In geological sciences, a simple acid test consists of placing a drop of dilute hydrochloric acid on a rock or mineral and observing if $\mathrm{CO}_{2}$ bubbles are released; the bubbles indicate the presence of carbonate minerals. This article describes a convenient method to estimate soil carbonate concentration using vinegar and other simple instruments for growers, Extension agents, and students interested in crop production and enhancing crop yield.

\section{Background and Setup}

\section{Principle}

The determination of carbonateis based on the following chemical reaction:

$\mathrm{CaCO}_{3}+2 \mathrm{H}^{+} \rightarrow \mathrm{Ca}^{2+}+\mathrm{CO}_{2} \uparrow+\mathrm{H}_{2} \mathrm{O}$
Vinegar is a dilute acetic acid solution that produces a weak effervescent reaction in contact with calcite. Carbon dioxide is released during the reaction and expressed as bubbles. Whether it is weak or vigorous, the bubbling depends on the quantity and particle size of soil tested. As a weak acid, acetic acid is safer to use than a strong acid such as hydrochloric acid.

\section{Reagent}

White vinegar with 5\% acidity (supermarket grade).

\section{Instruments}

- Eyedropper

- Cap (0.8 tsp volume) from bottled spring water

- Bowl (3.5 fl oz volume)

- Stirring rod

- Pen and paper

\section{Procedure}

1. Collect a composite soil sample that represents typical soil in the area, spread out, and dry it at room temperature for one week.

2. Remove gravel and large pieces of organic residue such as plant litter from the soil sample.

1. This document is HS1262, one of a series of the Horticultural Sciences Department, UF/IFAS Extension. Original publication date June 2015. Revised March 2018 and October 2021. Visit the EDIS website at https://edis.ifas.ufl.edu for the currently supported version of this publication.

2. Qiang Zhu, former postdoctoral associate, Horticultural Sciences Department; Yuncong Li, professor, Department of Soil and Water Sciences, UF/IFAS Tropical Research and Education Center; Guodong Liu, associate professor, Horticultural Sciences Department; and Monica Ozores-Hampton, former associate professor, UF/IFAS Southwest Florida Research and Education Center; UF/IFAS Extension, Gainesville, FL 32611.

The Institute of Food and Agricultural Sciences (IFAS) is an Equal Opportunity Institution authorized to provide research, educational information and other services

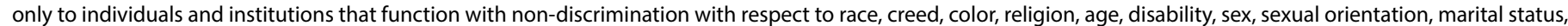

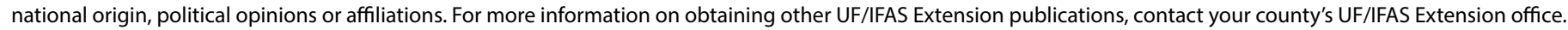
U.S. Department of Agriculture, UF/IFAS Extension Service, University of Florida, IFAS, Florida A \& M University Cooperative Extension Program, and Boards of County Commissioners Cooperating. Nick T. Place, dean for UF/IFAS Extension. 
3. Put one full cap of soil (Figure 1) into a bowl and add ten drops of spring water to wet the soil.

4. Use the eyedropper to add white vinegar to the soil sample in increments of ten drops at a time, stir the mixture thoroughly, and record the number of drops added.

5. When the vigorous bubbles become weak after stirring (Figure 2), stop adding vinegar and let the mixture stand for five minutes.

6. Add ten more drops, stir the mixture, and wait for one minute.

7. If only a few bubbles are released, stop and sum the number of drops used; if there are still a lot of bubbles, perform steps 4,5 , and 6 again.

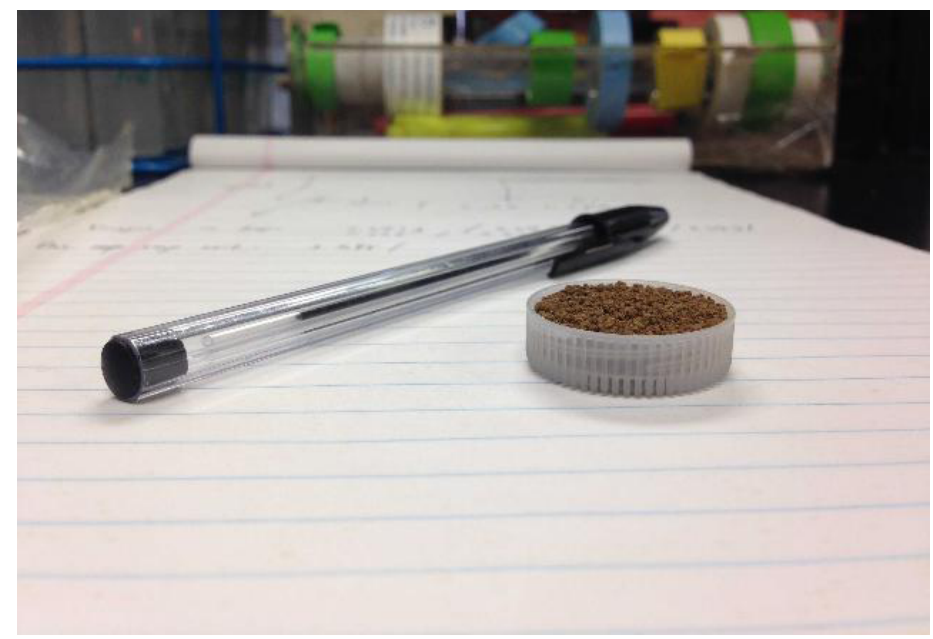

Figure 1. One full cap of soil. The volume of the cap is $0.8 \mathrm{tsp}$, and one cap dry soil is approximately 0.13 to $0.19 \mathrm{oz}$.

Credits: Q. Zhu, UF/IFAS

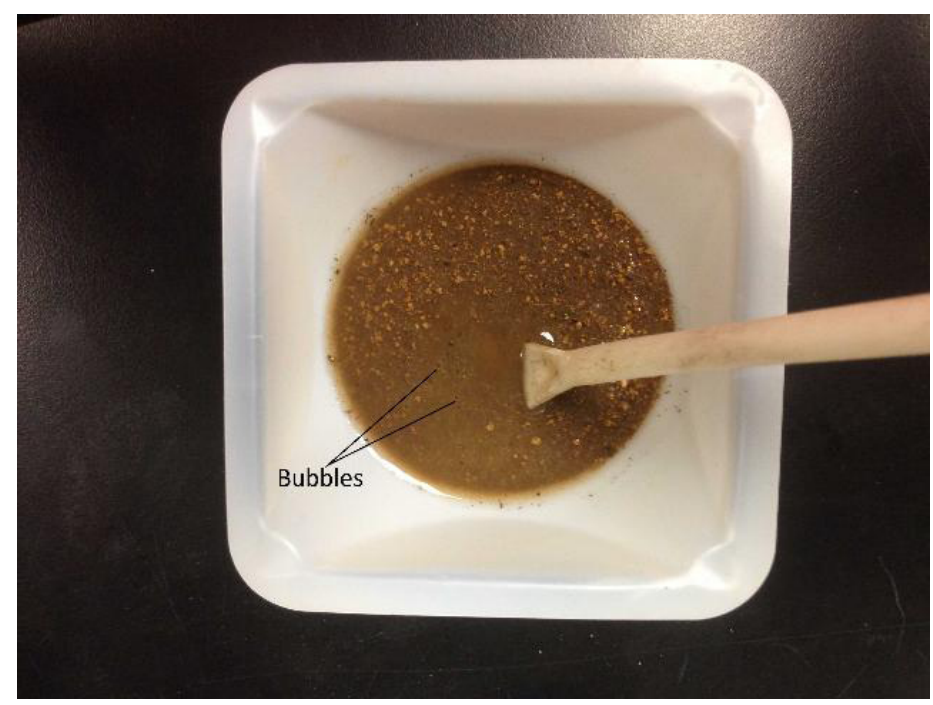

Figure 2. Vigorous bubbles become weak in the mixture of soil and vinegar.

Credits: Q. Zhu, UF/IFAS

\section{Interpretation of the Vinegar Test}

The vinegar test was compared to the volumetric calcimeter method, an accurate method to calculate calcium carbonate concentration (Chaney, Slonim, and Slonim 1982). The comparison showed a significant, positive linear correlation:

$y=10.63 x+1.12$

Where $y$ is carbonate concentration (\%) determined by volumetric calcimeter method and $\mathrm{x}$ is the slope (\%) of vinegar volume to soil mass, $\mathrm{R}^{2}=0.94$.

Therefore, soil carbonate concentration can be estimated using the vinegar test as indicated in Table 1. The table shows how carbonate concentration can be estimated by the total drops of vinegar added to one cap of soil. For example, if 50 drops of vinegar are recorded, the carbonate concentration will be $5 \%$; if 80 drops are used, then the concentration value will be in the range of $5 \%$ to $10 \%$.

\section{Acidifying Calcareous Soils}

Soil acidulants such as elemental sulfur, thiosulfate salts, or fertigation acids such as nitric acid, phosphoric acid, or sulfuric acid have been successfully used to acidify calcareous soils with less than $3 \% \mathrm{CaCO}_{3}$. However, soil acidulants will not acidify soil with high concentrations of $\mathrm{CaCO}_{3}(>10 \%)$ such as Krome, very gravelly loam, or Marl soils, which are found in south Florida. See Mylavarapu and Wiese (2016) for recommendations on lowering soil $\mathrm{pH}$ by elemental sulfur in soils with less than $3 \% \mathrm{CaCO}_{3}$.

\section{References}

Chaney, R. C., S. M. Slonim, and S. S. Slonim. 1982.

"Determination of Calcium Carbonate Content in Soils." In Geotechnical Properties, Behavior, and Performance of Calcareous Soils, edited by K. R. Demars and R. C. Chaney, 3-15. Baltimore, MD: American Society for Testing and Materials.

Mylavarapu, R., and C. Wiese. 2018. "Soil pH and the Home Landscape or Garden.” EDIS 2008 (2). https://edis. ifas.ufl.edu/ss480 
Table 1. Estimating soil carbonate concentrations with the vinegar test using one cup of soil.

\begin{tabular}{|c|c|}
\hline Number of drops for one cap ${ }^{2}$ of soil & Carbonate concentration (\%) \\
\hline$<10$ & $2-5$ \\
\hline $10-50$ & $5-10$ \\
\hline $50-100$ & $10-16$ \\
\hline $100-150$ & $16-21$ \\
\hline $150-200$ & $21-27$ \\
\hline $200-250$ & $27-32$ \\
\hline $300-350$ & $32-37$ \\
\hline $350-400$ & $37-43$ \\
\hline $400-450$ & $43-48$ \\
\hline $450-500$ & $48-53$ \\
\hline $500-550$ & $53-59$ \\
\hline $550-600$ & $59-64$ \\
\hline $600-650$ & $64-69$ \\
\hline
\end{tabular}

